\title{
Assessing medical students' competence in calculating drug doses
}

\author{
Authors: \\ Catherine Harries ${ }^{1}$ \\ Julia Botha ${ }^{1}$ \\ Affiliations: \\ ${ }^{1}$ School of Health Sciences, \\ University of KwaZulu-Natal, \\ South Africa \\ Correspondence to: \\ Catherine Harries \\ Email: \\ harriesk@ukzn.ac.za \\ Postal address: \\ Private Bag 7, Congella 4013, \\ South Africa \\ Dates: \\ Received: 13 Aug. 2012 \\ Accepted: 30 July 2013 \\ Published: 10 Sept. 2013 \\ How to cite this article: \\ Harries, C., \& Botha, J. \\ (2013). Assessing medical \\ students' competence in \\ calculating drug doses. \\ Pythagoras, 34(2), Art. \\ \#186, 9 pages. http://dx.doi. \\ org/10.4102/pythagoras. \\ v34i2.186

\section{Copyright:} \\ (C) 2013. The Authors. \\ Licensee: AOSIS \\ OpenJournals. This work \\ is licensed under the \\ Creative Commons \\ Attribution License.
}

Read online:
Evidence suggests that healthcare professionals are not optimally able to calculate medicine doses and various strategies have been employed to improve these skills. In this study, the performance of third and fourth year medical students was assessed and the success of various educational interventions investigated. Students were given four types of dosing calculations typical of those required in an emergency setting. Full competence (at the $100 \%$ level) was defined as correctly answering all four categories of calculation at any one time. Three categories correct meant competence at the $75 \%$ level. Interventions comprised an assignment with a model answer for self-assessment in the third year and a small group tutorial in the fourth year. The small groups provided opportunities for peer-assisted learning. A subgroup of 23 students received individual tuition from the lecturer prior to the start of the fourth year. Amongst the 364 eligible students, full competence rose from $23 \%$ at the beginning of the third year to $66 \%$ by the end of the fourth year. More students succeeded during the fourth than the third year of study. Success of small group tuition was assessed in a sample of 200 students who had formal assessments both before and after the fourth year tuition. Competence at the $75 \%$ level improved by $10 \%$ in attendees and decreased by $3 \%$ in non-attendees, providing evidence of the value of students receiving assistance from more able same-language peers. Good results were achieved with one-on-one tuition where individualised assistance allowed even struggling students to improve.

\section{Introduction}

Dosage errors are a cause of morbidity and mortality worldwide. Drug dosage calculations require basic mathematical literacy skills, but competence is inadequate amongst both medical students and qualified, practising doctors.

\section{Dosage calculation in practice}

Studies amongst doctors, nurses and paramedics confirm that many healthcare providers are not sufficiently competent in calculating drug doses (Coben, 2010; Conroy et al., 2008; Eastwood, 2009; McMullan, Jones \& Lea, 2010; Simpson, Keijzers \& Lind, 2009). Medical errors are a worldwide health concern, with dosage administration errors a key finding in the United Kingdom. Consequently, teaching the skills to calculate a dose correctly is an area that needs to be addressed in undergraduate courses (Coben, 2010; National Patient Safety Agency, 2009; Simpson et al., 2009).

Dosage calculation skills have not traditionally been taught to medical students. One explanation for this is that they require proportional reasoning skills; mathematics taught in school is thought to transfer to situations encountered outside school (Stasz, 2001). Consequently, it is assumed that these proportional reasoning skills are acquired at school, although it is not expected that the specific context of dosage calculation will have been encountered there. However, research suggests that mathematical knowledge transfer does not happen readily, partly because of differences between formal knowledge, which may involve mathematical algorithms, and contextual knowledge, which often involves contextual cues as part of the processing (Stasz, 2001).

\section{The cognitivist paradigm versus the sociocultural paradigm}

Historically, medical and mathematics teaching have operated within a normative or cognitivist paradigm. Within this paradigm, a skill is considered to be separate from the person acquiring the skill (or measuring the acquisition of the skill) as well as from the context within which it is learnt. It is thus expected that the skill will transfer readily from one context to another (Stasz, 2001). Accordingly, the context within which the skills will be needed is not considered relevant.

The objectification of skills and knowledge in this way has been criticised because it fails to consider the unique ability of the human 'to continually shape and be shaped by their social contexts' 
(Roth \& Lee, 2007, p. 4). Because the relevance of context is ignored, cultural diversity is not taken into account. It also fails to consider the unique ability of the human to interpret and represent experiences and it ignores or presumes its subjects' interpretation of situations (Cohen \& Manion, 1980). Consequently, the role of the relationship between teacher and student is regarded as limited to an opportunity for skills to be passed from the teacher to the student. The control over what is learnt, and how this is done, is with the teacher, the student not seen as needing a voice or requiring an opportunity to be heard. The teacher assumes a student is available to acquire skills if they have been delivered, that the student has then acquired these skills, or will if they make sufficient effort, and has sufficient ability to reinforce learning. The responsibility for the acquisition of the skills, once the teacher has delivered them, is believed to lie with the student.

In contrast, according to the Vygotskyan sociocultural view of learning, skills are learnt naturally within the context of social activity and within a culture using artefacts (such as language or, for dosage calculation, vials, syringes and treatment guidelines) developed within that culture. Accordingly, the skill cannot be understood without reference to the context, namely the development of skill with the socio-historically developed tools involved that mediate thinking, for example the language and equipment relevant to the activity (Rogoff, 1990, p. 35). These contextual factors give the skill its meaning and importance. This assists with motivation to acquire the skill. They provide pragmatic cues which improve performance and assist with retrieval of the skills in future use.

Within the context and culture of social activity there are relationships with other participants. Vygotsky's theory emphasises development as a process of learning to use the intellectual tools provided through social history (Roth \& Lee, 2007). Social interaction is expected to foster learning through the guidance provided within relationships with people who are skilled in the use of those intellectual tools (Rogoff, 1990). Accordingly, in a one-on-one relationship a novice will learn from an expert who guides as they participate in a meaningful activity. Key to the learning process within this paradigm is the relationship between novice and guide who engage together in dialogues, which may be tacit or non-verbal. Through these, a guide is able to hear the novice's voice and to be heard and to vary the amount of control needed to ensure the novice moves towards expertise. Within this paradigm, a student is recognised to be more or less available for learning and factors such as anxiety, motivation and distractibility are taken into account. The dialogues allow a guide to be responsive, in other words to provide a balance between support and challenge to keep the student optimally receptive to learning. Dialogues allow the guide to give just the right amount of challenge so that the activity is slightly beyond the learner's competence, within the learner's zone of proximal development. This Vygotskyan concept refers to the range of tasks that can be completed: the lower level of this zone corresponding to the level of skill that the learner can reach independently whilst the higher level refers to the potential skill level that can be completed with the assistance of the expert (Rogoff, 1990, p. 14). Learning is thought to occur through the relationship, which builds a bridge from the mind of the teacher to that of the learner so that the learner can borrow the perspective of the teacher to develop his own skills (Rogoff, 1990, p. 19).

Consequences of the prevailing positivist paradigm to students is that (1) the context particular to dosage calculation has not been provided, hampering retrieval, (2) although proportional reasoning skills may have been acquired at school, these skills may have been taught in the early school years only, and half-forgotten as the students focused on more abstract mathematics, and (3) skills may not have been adequately taught or acquired leaving students incompetent in this area of mathematics, but without a guiding relationship within which to communicate the need for support, possibly leading to anxiety. Aversion towards mathematics is a common phenomenon amongst students in higher education (Taylor \& Galligan, 2006) and such anxiety might lead to increased defensiveness, which might prevent them from seeking help at medical school and later from checking answers with colleagues in a clinic situation.

\section{Lack of focus on teaching therapeutics}

An approach that may remediate some of the problems of earlier learning within a positivist paradigm is that of problem-based learning (PBL), in which students are presented with a problem that forms the starting point and focus of learning. Students use a problem-solving routine interactively to identify what their learning needs are in order to manage the problem; they then use self-directed learning to meet these needs and then meet to discuss and summarise what they have learnt. A well-designed PBL programme is expected to improve the integration of prior learning with new information, the transfer of skills to a real-life setting and the elaboration of knowledge for better understanding and retention. An established result of PBL research is increased student motivation (Albanese \& Mitchell, 1993). There has been widespread adoption of forms of this approach amongst medical schools worldwide since its introduction at the McMaster University School of Medicine in the late 1960s. A problem-based learning medical curriculum has been followed at our (the authors') School of Medicine in KwaZulu-Natal since 2001, with several modifications since 2006 to include an instructor-led basic science module at the beginning of the first year (to provide cognitive scaffolding) and more clinical bedside teaching in the fourth year (Tufts \& Higgins-Opitz, 2012).

According to the PBL approach, our students, in small groups and guided by a facilitator, develop common learning goals from a paper case related to a medical theme and report back. Students are expected to reach these goals individually, with support from useful literature, structured learning sessions, tutorials, practicals and clinic or hospital visits. 
To some extent, the problem-based learning approach has remedied students' lack of exposure to context because the paper cases provide students with some of the contextual factors of real-life health problems. However, the paper cases focus on diagnosis and less attention is paid to the details of treatment, including the technicalities of prescribing, such as calculating the correct dose. The failure of curricula to emphasise prescribing and teaching the skill to treat the patient' is a cause of concern internationally (Hogerzeil et al., 2001). As a therapeutics department, we aimed to improve prescribing competence by offering a programme of therapeutics learning opportunities relevant to the medical themes being discussed, largely in the form of large group sessions and assignments because these fit most readily into complicated timetables.

In light of the inadequate dosage skills amongst doctors and students (Simpson et al., 2009; Wheeler et al., 2004) we (the authors) felt that dosage skills training should be introduced to the medical curriculum. We believed we were best placed to provide the context relevant to dosage calculations and, like Huijser, Kimmins and Galligan (2008), that students 'would learn better if the mathematical skills required for dosing were taught as an integral part of our programme, rather than separated and remediated in a content vacuum' (pp. A-24). Accordingly we set about including dosage calculation training in some of our therapeutic learning opportunities so that students could have opportunities to access prior mathematical skills as well as to determine and remediate missing mathematical skills.

For example, within the endocrine theme, where students are introduced to the body's hormones, one of the students' PBL cases focused on a patient who developed hypercalcaemia (abnormally high levels of calcium in the blood) as a result of overproduction of the hormone involved in controlling the level of calcium in the blood (parathyroid). Our learning session initially focused on which medicines would be used to manage this condition and how these medicines worked. In this case, an appropriate option is the administration, by intravenous infusion, of the medicine pamidronate.

In order to bring in the dosage calculation skills students needed to manage this case, students were provided with dosage information and asked to consider how this drug should be reconstituted from a powder to a solution, what volume of this solution should be added to a litre of normal saline and what drip rate should be set in order for this infusion to be given over 6 hours.

\section{The calculation process}

In contrast with medical students, nursing students have historically received dosage calculation skills training. Common practice is to teach, according to rule-based strategy, a formula known as 'the nursing rule' (Hoyles, Noss \& Pozzi, 2001, p. 13), explained by nurses as 'what you want over what you've got, times the volume it comes in,' or in its written form: $\frac{\text { What you want }}{\text { What you've got }} \times$ The volume it comes in

We illustrate the use of this formula in solving the following example:

Problem:

A child is to be sedated with $1.5 \mathrm{mg}$ of midazolam. A vial of midazolam has $15 \mathrm{mg}$ in $3 \mathrm{~mL}$. How many millilitres of midazolam are required?

\section{Solution:}

What you want $=$ the amount of drug prescribed $=1.5 \mathrm{mg}$. What you've got $=$ the amount of drug dissolved in the formulation $=15 \mathrm{mg}$.

The volume it comes in $=3 \mathrm{~mL}$

So when the formula is applied:

$\frac{1.5 \mathrm{mg}}{15 \mathrm{mg}} \times 3 \mathrm{~mL}=0.3 \mathrm{~mL}$

Shortcomings associated with using formulae are recognised. Coben et al. (2010) contrast memorising a formula with developing a competence where,

when presented in a particular context with a prescription with a specified dose, an ampoule with a particular strength and volume and a choice of syringes with which to draw it up, a student can manipulate these to produce the correct prescribed dose. (p. 4)

A formula may be forgotten when it is needed in practice or the vague terms involved may lead to the inclusion of incorrect values; for example, 'what you've got' may be understood as the concentration rather than the amount of drug and this wrong information would lead to calculation of the wrong dose.

Various educational interventions have been implemented and found to improve dosage skills amongst nursing students. In comparison with traditional lectures, where formulae (such as the nursing rule) were taught, significantly higher sustained learning was reported with methods that built on students' existing mathematical problem-solving skills and focused on avoiding conceptual errors (Gillies, 2004; Koohestani \& Baghcheghi, 2010). With this in mind, we avoided the mechanistic use of formulae.

Vergnaud's (1982) model of proportionality includes a multiplicative structure involving direct proportion between two measure spaces. Determination of an appropriate volume of a drug in a solution could be characterised by this structure, the measure spaces being the mass of the drug and the volume of the solution. According to this model, the correct volume of a drug could be obtained either by rule-based, functional or scalar approaches. The first two approaches involve manipulating figures across measured spaces, whilst the last (that is the scalar approach) involves working only within measure spaces by adopting various strategies. Nurses, although generally taught rule-based 
strategies, most commonly adopt scalar strategies in a clinical setting (Hoyles et al., 2001). Scalar approaches to solving proportionality problems are more flexible and generalisable to the workplace, preserving the meaning of the quantities and their relationship by keeping variables separate (Nunes, Schliemann \& Carraher, 1993).

In view of these findings, we adopted a scalar approach to solving dosage problems in our large group sessions to help keep students in touch with the meaning of the quantities. We called it the 'two column stepwise method' in which 'whatever was done' to one column (one measure space: mass) 'was done' to the other (the second measure space: volume). In other words the same arithmetical calculation was applied to each measure space.

Corresponding with the unitary method (one of the scalar strategies described by Vergnaud (1982), the initial step is to reduce the quantity in the first space to unity (one). This is illustrated in Figure 1 using the problem and solution below.

\section{Problem:}

A child is to be sedated with $1.5 \mathrm{mg}$ of midazolam. A vial of midazolam has $15 \mathrm{mg}$ in $3 \mathrm{~mL}$. How many millilitres of midazolam are required?

\section{Solution:}

In order to get from $15 \mathrm{mg}$ to $1.5 \mathrm{mg}$ the first 'step' is to get to $1 \mathrm{mg}$ by dividing the number by itself (in this case 15). The same divisor is then applied to the second column (volume). Next, the resultant numbers in both columns are multiplied by 1.5 .

After this, students are required to be pragmatic and to check, in a different way, that the answer 'makes sense'. This means appraising whether the result obtained is feasible. For example, in the above example a different scalar approach can be used to see if the answer 'looks' sensible: $1.5 \mathrm{mg}$ is a tenth of $15 \mathrm{mg}$, so a tenth of $3 \mathrm{~mL}$ is needed and a tenth of 3 $\mathrm{mL}$ equals $0.3 \mathrm{~mL}$.

The 'two column stepwise method', followed by the pragmatic check, was used in all large group sessions, report backs and model answers.

\section{The sociocultural perspective and best teaching practices}

In our efforts to design appropriate and effective dosage calculation training we were cognisant of the fact that the

\begin{tabular}{|c|c|}
\hline Mass space (milligram) & Volume space (millilitre) \\
\hline \multirow[t]{2}{*}{$15 \mathrm{mg}$} & $3 \mathrm{~mL}$ \\
\hline & \\
\hline \multirow{3}{*}{$1 \mathrm{mg}$} & $3 \mathrm{~mL}$ \\
\hline & 15 \\
\hline & \\
\hline $1.5 \mathrm{mg}$ & $\frac{3 \mathrm{~mL}}{15} \times 1.5=0.3 \mathrm{~mL}$ \\
\hline
\end{tabular}

FIGURE 1: Illustration of the 'two column stepwise method.' students and medical school operate within the context of a newly democratic post-conflict society in which continuing poverty and inequality exist. Within this society there are two needs affecting curriculum decisions: one is the focus on equity and social justice to redress historical inequality and the other is the drive to develop skills for further learning and participation in a globalised and increasingly technological workplace (Vithal, 2012). Teaching within the sociocultural paradigm, which requires students to have a voice and to participate in the learning process whilst still being guided by the societal need for competent prescribers, would meet these needs.

Accordingly, we aimed to improve learning from the sociocultural perspective, within the constraints of the teaching interactions we could readily provide for students, namely the large group session and assignment for selfassessment. One of the goals relevant to large group sessions would be to provide meaningful tasks that closely resemble those that must be undertaken in the workplace as a focus for joint attention. Although resource and safety restraints precluded the use of real tasks, we developed paper dosage calculation problems of patients receiving drug treatment for conditions relevant to the current theme, using formulations and dosage regimens that would be encountered in practice in order to preserve sufficient meaning for learning to occur and be transferable to a clinic setting, as advocated by Coben (2010, p. 10).

We also took guidance from the seven hallmarks of good practice in undergraduate education, as described by Chickering and Gamson (1987). These were developed from 50 years of student and teacher experience and research and are widely regarded as a gold standard for measuring the quality of undergraduate education. These guidelines include encouraging student-faculty contact (improving studentteacher communication would be an important part of this contact), developing cooperation and reciprocity amongst students, participating in active learning, providing prompt feedback, communicating high expectations, respecting diversity and emphasising the necessity of dedicating time to the acquisition of a skill ('time on task'). These guidelines fit well with the sociocultural paradigm because the seven principles would be expected to occur within the social dialogues between a learner and a teacher or a more competent learner working together on a meaningful activity.

\section{Our teaching}

After we included dosage calculation training in our large group sessions and assignments, with a particular focus on real-life contextual examples, we assessed student competence as the years progressed. This allowed us to evaluate the impact of 'time on task'. In an effort to improve student dosage competence further we aimed to enrich the interaction between learners and experts (whether teachers or more capable students) in our interventions. We gave individual students one-on-one tuition (strengthening student-teacher 
contact) and offered a tutorial that allowed for peer-assisted learning (developing cooperation and reciprocity amongst students).

\section{Objectives and research questions}

Our teaching provided the opportunity to examine the impact of three of Chickering and Gamson's principles (1987, p. 3) and consequently our research questions were: What is the effect of (1) time on task, (2) peer-assisted learning and (3) closer student-teacher contact on dosage calculation competence amongst medical students?

\section{Research design Materials and setting}

We examined the responses of medical students at our School of Medicine in KwaZulu-Natal to dosage calculation problems included in examinations during their third and fourth years. We also examined case notes, written responses to paper problems and interview transcripts collected during the individual tuition of 23 of these students who were selected from those who were not able to dose competently by the end of their third year.

Most of the students started medical school immediately after leaving school and the median age of our group was 21 years with a range of $18-34$, as a few students already had other degrees. There is considerable diversity in terms of both culture and educational background, with students drawn from homes with eleven different languages other than English. The majority of students come from government schools, some of which were historically disadvantaged in terms of resources and access to skilled teaching. Other students come from advantaged privately funded schools, both in South Africa and neighbouring African countries.

\section{Design and procedure}

Medical students at our School of Medicine were exposed to various different dosage calculation training methods during their third and fourth years of study. Paper problems involving formulations of medicines and regimens included in the South African Standard Treatment Guidelines (Department of Health, 2008) were used as training and assessment material. The calculations were of four different types, namely the determination of a drip rate and three calculations where the concentration of drug was expressed in three different ways: in units of mass per volume (e.g. midazolam labeled as $5 \mathrm{mg} / \mathrm{mL}$ ), as a ratio (e.g. adrenaline 1:1000) and as a percentage (e.g. 1\% lignocaine).

Every assessment comprised four questions, one of each type. These were randomly selected from a bank of appropriate questions. Students were deemed competent at the 100\% level if they got all four calculations correct at any one time. At least three of the four questions correct meant they were competent at least at the $75 \%$ level.

After a baseline test at the beginning of third year, students were assessed repeatedly and the cumulative number of students attaining competence by their final assessment in their third and fourth year was measured. In order to investigate the effect of 'time on task' advocated by Chickering and Gamson (1987), competence acquired in the third year was compared with that achieved in the fourth year.

In the third year, students were given an hour-long introductory lecture and an assignment, followed a week later by a report-back session and a model answer for selfassessment. In fourth year, in an effort to improve 'peer contact' as advocated by Chickering and Gamson (1987, p. 3), they were offered a further lecture followed by a tutorial in which they worked together through examples. It was hoped that this peer-assisted teaching strategy would help to overcome language barriers, as students would be able to seek assistance from more able same-language peers. A sample of 200 of these students were given formal assessments both before and after the extra tuition. The change in calculation competence was compared between those who attended and those who did not.

In an attempt to test the value of increasing 'contact between students and faculty' (Chickering \& Gamson, 1987, p. 3), 23 students were offered individual tuition prior to the start of the fourth year. After giving written consent, each was asked to work through dosage calculations that they had previously answered incorrectly. If they faltered, the researcher would provide just sufficient information or explanation to enable the student to continue and would make a note of the difficulty experienced by the student. The interview transcripts, written calculations and case notes were analysed to determine common key problems experienced by the students. The influence of one-on-one teaching on student competence was assessed retrospectively by comparing their results for assessments immediately before and after this tuition.

There were two subgroups in this group of 23 students. The first $(N=13)$ was sampled from those who in previous tests had omitted questions or made errors where the student's reasoning could not be followed. The sample was stratified across the range of student ability. The second subgroup $(N=10)$ was a convenience sample from the poorest performing students. There were 38 such students all of whom were invited but only ten chose to attend. Details of the training offered to the different groups of students are provided in Table 1.

TABLE 1: Training offered.

\begin{tabular}{llll}
\hline Group & Whole group time on task $(\boldsymbol{N = 3 6 4 )}$ & Tutorial peer-assisted learning $(\boldsymbol{N}=\mathbf{2 0 0})$ & One-on-one tuition faculty-assisted learning $(\boldsymbol{N}=\mathbf{2 3})$ \\
\hline Third year & Lecture & Lecture & Lecture \\
& Assignment and model answer & Assignment and model answer & Assignment and model answer \\
Fourth year & Revision lecture and tutorial & Revision lecture and tutorial & One-on-one faculty teaching \\
& & & Revision lecture and tutorial \\
\hline
\end{tabular}

$N=$ number of students assessed in each group. 


\section{Statistical analysis}

Epi-Info version 3.5.3, a public domain statistical software package for epidemiology (Centre for Disease Control and Prevention, 2011), was used to perform Chi-squared tests and risk ratio calculations to investigate demographic factors, including race and English as a home language, as predictors of performance, as well as to compare change in calculation competence between group tutorial attendees with those who did not attend these sessions. Statistical significance was set at a level of $5 \%$ or less (i.e. $p<0.05$ ).

QSR NVivo 8, a software package for qualitative data analysis (QSR International, 2008), was used to analyse the material related to the students given individual teaching sessions to determine the key problems they experienced.

\section{Reliability}

In order to ensure the reliability of results, our questions were based on a tested instrument to assess dosage competence. This instrument comprised questions from an Australian study (Simpson et al., 2009). We modified this instrument slightly where necessary to reflect dosage formulations and regimens used in South Africa.

\section{Validity}

In order to ensure that our measurement of student ability would reflect their ability as future doctors to dose their patients appropriately, we aligned our teaching and assessment materials as closely as possible with situations that will be encountered when prescribing and administering a drug. We used the prevailing prescribing regimens and formulations recommended by the texts that guide prescribing in South Africa, the South African Standard Treatment Guidelines (Department of Health, 2008) and South African Medicines Formulary (University of Cape Town Division of Clinical Pharmacology, 2010). Students were provided with pictures and explanations of materials and equipment peculiar to the task of dosing drugs, such as vials, ampoules, powders requiring reconstitution, administration sets and infusion solution bags. The assessment questions selected were typical of those encountered in an authentic emergency setting.

\section{Ethical considerations}

Ethical approval (reference number BE185/09) for this mixed-methods study was obtained from the University's Biomedical Research Ethics Committee. After being given written information, each participant gave their written informed consent to the written publication in a research journal of the overall findings from their data.

\section{Findings}

Of the 364 students eligible for the study, 82 were found to be competent at the $100 \%$ level at the beginning of their third year. Of the 282 remaining, 58 (20.6\%) were competent by the end of third year. By their last test in fourth year, 99 of the remaining $224(44.2 \%)$ had attained competence. Thus, more students became fully competent during the fourth than during the third year. Likewise in the third and fourth year respectively, $29.6 \%$ and $54.9 \%$ of students became newly competent at the $75 \%$ level (Table 2). At each screening stage, students who did not achieve full competencebut who attained competence at the $75 \%$ level were most commonly prevented from achieving full success by a mistake with a calculation involving concentrations expressed as a ratio or percentage (each between $31 \%$ and $43 \%$ of the time). Mistakes with mass per volume and drip rate questions which prevented full competence were made in between $6 \%$ and $22 \%$ of cases. Of the 364 students, 51\% were English speaking whilst the rest spoke an African language at home. The average age was 21 years with an age range of 18-34 years. Over half (59\%) were female students. Although race and home language were predictors of performance at baseline, both associations had been lost by the final assessment. Neither age nor gender was associated with competence either at the beginning or the end of the study.

In the subgroup of 200 students who had formal assessments both before and after the fourth year group tutorial, 83 were attendees and 117 non-attendees. Attendees performed better overall before tuition, $30 \%$ and $55 \%$ of them scoring $100 \%$ competency and $75 \%$ competency respectively. Equivalent figures for non-attendees were $21 \%$ and $53 \%$. Attendance made no difference to students' ability to achieve $100 \%(0 \%$ and $3 \%$ change for attendees and non-attendees respectively (Table 3). However, attendance had a significant influence on

TABLE 2: Number and percentage of students competent over time $(N=364)$.

\begin{tabular}{|c|c|c|c|c|c|c|c|c|}
\hline \multirow[t]{2}{*}{ Screening stage } & \multicolumn{2}{|c|}{ Number competent at } & \multicolumn{2}{|c|}{ Number not yet competent at } & \multicolumn{2}{|c|}{ Percentage competent at } & \multicolumn{2}{|c|}{ Percentage newly competent at } \\
\hline & $100 \%$ level & $75 \%$ level & $100 \%$ level & $75 \%$ level & $100 \%$ level & $75 \%$ level & $100 \%$ level & $75 \%$ level \\
\hline Start of third year & 82 & 172 & 282 & 192 & $23 \%$ & $47 \%$ & - & - \\
\hline End of third year & 140 & 232 & 224 & 132 & $38 \%$ & $64 \%$ & $21 \%$ & $30 \%$ \\
\hline End of fourth year & 239 & 305 & 125 & 59 & $66 \%$ & $84 \%$ & $44 \%$ & $55 \%$ \\
\hline
\end{tabular}

$N=$ number of students.

TABLE 3: Percentage of students competent before and after peer-teaching intervention $(N=200)$

\begin{tabular}{|c|c|c|c|c|}
\hline \multirow[t]{2}{*}{ Screening stage } & \multicolumn{2}{|c|}{ Attendees $(N=83)$} & \multicolumn{2}{|c|}{ Non-attendees $(N=117)$} \\
\hline & $100 \%$ competence & $75 \%$ competence & $100 \%$ competence & $75 \%$ competence \\
\hline Beginning of third year baseline & $14 \%$ & $34 \%$ & $11 \%$ & $43 \%$ \\
\hline End of third year before intervention & $30 \%$ & $55 \%$ & $21 \%$ & $53 \%$ \\
\hline End of fourth year after intervention & $30 \%$ & $65 \%$ & $24 \%$ & $50 \%$ \\
\hline
\end{tabular}

$N=$ number of students. 
the numbers of students achieving $75 \%$ competency $(10 \%$ and $-3 \%$ changes for attendees and non-attendees respectively, $p$ $<0.05)$. There was no statistical difference in improvement for any of the four different types of question between the attendees and non-attendees.

Regarding the one-on-one teaching, in the group with the range of abilities $(N=13)$, three students did not attend the final assessment. The remaining 10 all finally achieved 100\% - four having started at $25 \%$, four at $50 \%$ and two at $0 \%$ (Table 4).

In the subgroup comprising the very weakest students $(N=10)$, three students did not complete the final assessment. There was an improvement amongst the remaining seven, most of whom started with $0 \%$. The marks of three improved from 0 to $50 \%$ and one each from 0 to $25 \%, 0$ to $75 \%, 0$ to $100 \%$ and 25 to $50 \%$ (Table 5).

During the interviews, it was apparent that students most frequently had difficulties with the concentration of a solution expressed as a ratio or percentage. The next most commonly encountered problem was unit conversion, for example converting from milligrams to grams or micrograms to milligrams.

The group comprising very poor students had the additional difficulty that, despite our efforts, they still did not understand that the concentration of a solution is actually giving information about the quantity or mass of a substance relative to the volume, in other words two variables. This group was also overly reliant on calculators. They lacked an ability to simplify numbers or see patterns and had no insight into an unrealistic number generated by the calculator.

\section{Discussion}

More students became competent, at both the $100 \%$ and $75 \%$ level, during the fourth than during the third year of study. This could be due, in part, to the fact that by fourth year students had had more calculation practice. There is some evidence of this in that a small number of students improved to the $100 \%$ level even though they did not attend the group tuition. In other words, repeated learning and assessment over two years allowed students to benefit from spending 'time on task', consistent with the findings of Chickering and Gamson (1987, p. 3). Celebi, Weyrich, Kirchoff and LammerdingKoppel (2009) found an improvement in prescribing skills even amongst a control group of students and attributed this to a training effect as students gained practice with the assessment method. Amongst nurses, inclusion over three years in drug calculation learning opportunities, which gradually increased in difficulty, and repeated assessment were found to be successful strategies (Elliott \& Joyce, 2005). For students achieving at the 75\% level of competence but failing to attain full competence, calculations involving concentrations expressed as a ratio or percentage presented the most difficulty. Such calculations have also been found to present the greatest difficulty in other studies (Simpson et al., 2009; Wheeler et al., 2004).
TABLE 4: Dosage results for stratified sample of students given one-on-one teaching.

\begin{tabular}{lccccc}
\hline Score achieved & $\mathbf{0 \%}$ & $\mathbf{2 5 \%}$ & $\mathbf{5 0 \%}$ & $\mathbf{7 5 \%}$ & $\mathbf{1 0 0 \%}$ \\
\hline Beginning of third year $(N=13)$ & 6 & 4 & 3 & 0 & 0 \\
$\begin{array}{l}\text { End of third year }(N=13) \\
\text { before intervention }\end{array}$ & 4 & 4 & 4 & 1 & 0 \\
$\begin{array}{l}\text { End of fourth year }(N=10) \\
\text { after intervention }\end{array}$ & 0 & 0 & 0 & 0 & 10 \\
\hline$N=$ number of students. & & & &
\end{tabular}

TABLE 5: Dosage results for sample of very weak students ( $N=10 ; 3$ not included in final assessment).

\begin{tabular}{lccccc}
\hline Score achieved & $\mathbf{0 \%}$ & $\mathbf{2 5 \%}$ & $\mathbf{5 0 \%}$ & $\mathbf{7 5 \%}$ & $\mathbf{1 0 0 \%}$ \\
\hline Beginning of third year $(N=10)$ & 6 & 3 & 1 & 0 & 0 \\
$\begin{array}{l}\text { End of third year }(N=10) \\
\text { before intervention }\end{array}$ & 6 & 3 & 1 & 0 & 0 \\
$\begin{array}{l}\text { End of fourth year }(N=7) \\
\text { after intervention }\end{array}$ & 0 & 1 & 4 & 1 & 1 \\
\hline
\end{tabular}

$N=$ number of students.

There was significant improvement in those students who attended the group tuition. Besides affording students dedicated time to focus on calculations away from competing priorities, the small groups provided more intimacy as there were fewer students present than in lectures. This gave students the opportunity to learn from more competent peers who may have guided them through difficult steps and clarified areas of misunderstanding. This finding is in line with the advantage of peer-assisted learning proposed by Chickering and Gamson (1987). In a group of nursing students, guidance from mentors and informal opportunities to engage with slightly more competent peers were also found to be helpful (Penman \& White, 2006). Help and support from peers also afforded an opportunity for theorisation of learning in a more accessible language as, because there are 11 official languages and limited personnel within these language groups with appropriate teaching skills, teaching and assessments are entirely conducted in English. It is interesting to note that, by the end of our study, not speaking English at home had been lost as a risk factor for poor calculation competence.

One-on-one teaching markedly improved competence. All randomly selected students achieved $100 \%$ and even in the group selected from the poorest students, most improved. Our success with individual tuition is consistent with Vygotsky's theory of learning: when the informal, disorganised concepts of the learner meet with the formal, methodical reasoning of the teacher this allows for co-regulation between the teacher and the student (Fogel, 1993). This state of inter-subjectivity between the student and the teacher enables the teacher to guide the student forward toward a better understanding of a situation (Kolikant \& Broza, 2011).

Students who participated in the one-on-one interventions also had good attendance at the group tuition, so their results are a reflection of both group and individual tuition. It may be that the competence they developed during the individual tuition motivated them to attend the group tuition.

During the one-on-one interviews, it was apparent that students' most common problems related to selecting the 
appropriate units to express a concentration given as a ratio or percentage. This was in line with findings from the written assessment, where such questions were more problematic for students achieving at the $75 \%$ level of competence but failing to attain full competence. In the randomly selected group of interview students, once this was clarified they were able to develop competence and master the calculations. The next most common problem, namely that with unit conversion, was also improved with individual teaching.

The group comprised of the very weakest students had additional conceptual problems that benefitted in particular from the one-on-one tuition. This was consistent with Jackson and De Carlo (2011), who found that nursing students with conceptual deficiencies required more rigorous remediation. Similarly, Kolikant and Broza (2011) contend that lowachieving students need appropriate interventions to improve their conceptual understanding.

The very weak group struggled with the concept of the strength of a solution and the idea that a ratio or percentage can describe the relationship between the amount of drug in a solution and the volume of that solution. This suggests that they had difficulty handling intensive quantities, which are measured by a relation between two variables. Concentration (an intensive quantity) is measured in terms of units of mass per units of volume. Reasoning about intensive quantities has been shown to be difficult for school children who lack opportunities in school to develop this understanding (Nunes, Desli \& Bell, 2003).

Although one-on-one teaching may seem like a luxury in a world where cost-cutting exercises make it a rarity, it does have benefits beyond the obvious; Huijser et al. (2008) noted that 'meanings negotiated during one-on-one consultations are not a one-way street, but rather part of a mutual learning experience during which valuable insight is gained'. They noted that individual teaching provides the opportunity for teacher responsiveness not only to the learner receiving the individual tuition but, by allowing misconceptions to be identified, to the group as a whole. Likewise, once our individual teaching had revealed that understanding related to intensive quantities could not be taken for granted, we changed our overall practice. We now include visual representations of particles in solution in our large group learning. We also make the analogy that when a large cup of sweet tea is poured into smaller cups it maintains the same sweetness (concentration), although the amount of sugar and volume of liquid in each cup is less.

Once students are reminded of their understanding of intensive quantities in this way, the idea that drug concentrations describe the relationship between two quantities (or Vergnaud's two measure spaces) is introduced. The teacher now describes a hypothetical 1\% solution, asking students to imagine $1 \mathrm{~g}$ of powdered active ingredient dissolved in $100 \mathrm{~mL}$ of water and then poured into each of one hundred $1 \mathrm{~mL}$ ampoules. Attention is drawn to the fact that the concentration has not changed; it remains $1 \%$.
The very weak students were also overly reliant on calculators. This may have contributed to their lack of insight into an unrealistic result generated by a calculator. McMullan et al. (2010) found that young nurses who had relied on calculators since school had a false sense of security, resulting in more conceptual errors. Gillies (2004) has also expressed concern that unquestioning learning of a formula as well as over-reliance on a calculator could prevent students from monitoring their calculations thoughtfully causing them to blindly accept results, abandoning common sense and resulting in the acceptance of clearly unreasonable answers (Gillies, 2004).

\section{Conclusion}

Our study found that student competence improved with repeated exposure and training using the scalar 'two column stepwise method'. Group tuition helped struggling students to improve further, confirming the value of providing opportunities for learners to focus jointly on authentic paper problems with teachers or more capable peers. Although time consuming, one-on-one tuition achieved good results with individualised assistance, allowing even the very poorest students ultimately to improve. The insight gained from these interactions allowed us to provide responsive subsequent learning interactions. Accordingly we modified our programme to incorporate interventions focused on the understanding of intensive quantities.

\section{Acknowledgements}

We would like to thank Elizabeth Nicolosi for her assistance with capturing the data.

\section{Competing interests}

We declare that we have no financial or personal relationships that may have inappropriately influenced us in writing this article.

\section{Authors' contributions}

C.H. and J.B. (both from University of KwaZulu-Natal) were responsible for experimental and project design. C.H. performed the data collection and statistical analysis. C.H. and J.B. collaborated in writing the manuscript.

\section{References}

Albanese, M.A., \& Mitchell, S. (1993). Problem-based learning: A review of literature on its outcomes and implementation issues. Academic Medicine, 68(1), 52-81. http://dx.doi.org/10.1097/00001888-199301000-00012, PMid:8447896

Celebi, N., Weyrich, P., Kirchoff, K., \& Lammerding-Koppel, M. (2009). Problem-based training for medical students reduces common prescription errors: A randomized controlled trial. Medical Education, 43, 1010-1018. http://dx.doi.org/10.1111/ j.1365-2923.2009.03452.x

Centre for Disease Control and Prevention. (2011). Epi-Info (Version 3.5.3). Available from http://www.cdc.gov/globalhealth/gdder/ierh/researchandsurvey/enasoftware.htm

Chickering, A., \& Gamson, Z. (1987). Seven principles for good practice in undergraduate education. American Association for Higher Education \& Accreditation Bulletin, 39(7), 3-7. Available from http://www.aahea.org/aahea/ Accreditation Bulletin, 39(7), 3-7. Av
articles/sevenprinciples1987.htm

Coben, D. (2010, March). At the sharp end of education for an ethical, equitable and numerate society: Working in a safety-critical context-numeracy for nursing. In Proceedings of the 6th International Mathematics Education and Society Conference, Berlin, Germany (pp. 9-22). Available from http://www.ewi-psy.fuberlin.de/en/v/mes6/documents/plenary/Diana_Coben_MES6.pdf 
Coben, D., Hall, C., Hutton, M., Rowe, D., Sabin, M., Weeks, K., et al. (2010). Numeracy for nursing - Creating a benchmark. In D. Coben, \& J. O'Donoghue (Eds.), Adult mathematics education: Papers from Topic Study Group 8, 11th International Congress on Mathematical Education (pp. 148-164). Limerick: NCE-MSTL. Congress on Mathematical Education (pp.
Available from http://tsg.icme11.org/tsg/show/9

Cohen, L., \& Manion, L. (1980). Research methods in education. London: Croom Helm.

Conroy, S., North, C., Fox, T., Haines, L., Planner, C., Erskine, P., et al. (2008). Educational interventions to reduce prescribing errors. Archives of Disease in Childhood, 93, 313-315. http://dx.doi.org/10.1136/adc.2007.127761

Department of Health. (2008). Standard treatment guidelines and essential medicines list for primary health care. Pretoria: Department of Health. Available from http:// www.kznhealth.gov.za/edlphc2008.pdf

Eastwood, K.J. (2009). Can paramedics accurately perform drug calculations? Emergency Medicine Journal, 26(2), 117-118. http://dx.do.org/10.1136/emj.2008.070789

Elliott, M., \& Joyce, J. (2005). Mapping drug calculation skills in an undergraduate nursing curriculum. Nurse Education in Practice, 5, 225-229. http://dx.doi. org/10.1016/j.nepr.2004.12.003

Fogel, A. (1993). Developing through relationships. Chicago: University of Chicago Press.

Gillies, R. (2004). Numeracy for nurses: The case for traditional verses non-traditional methods for teaching drug calculation. In I. Putt, R. Faragher, \& M. McLean (Eds.), Proceedings of the 27th Annual Conference of the Mathematics Education Group of Australasia (pp. 255-262). Townsville: MERGA. Available from http://www. merga.net.au/documents/RP292004.pdf

Hogerzeil, H.V., Barnes, K.I., Henning, R.H., Kocabasoglu, Y.E., Moller, H., Smith, A.J., et al. (2001). Teacher's guide to good prescribing. Geneva: World Health Organization. Available from http://www.who.int/medicinedocs/pdf/s2292e/ s2292e.pdf

Hoyles, C., Noss, R., \& Pozzi, S. (2001). Proportional reasoning in nursing practice. Journal for Research in Mathematics Education, 32(1), 4-27. Available from http://www.jstor.org/stable/749619

Huijser, H., Kimmins, L. \& Galligan, L. (2008) Evaluating individual teaching on the road to embedding academic skills. Journal of Academic Language and Learning, 2(1), A23A38. Available from http://journal.aall.org.au/index.php/jall/article/view/61/54

Jackson, N.V., \& De Carlo, J.J. (2011). Problem solved: Dosage calculation in a nursing program. Nurse Educator, 36(2), 80-83. http://dx.doi.org/10.1097/ NNE.Ob013e31820b532b

Kolikant, Y.B., \& Broza, A. (2011). The effect of using a video clip presenting a contextual story on low-achieving students' mathematical discourse. Educational Studies in Mathematics, 76, 23-47. http://dx.doi.org/10.1007/s10649-010-9262-5

Koohestani, H., \& Baghcheghi, N. (2010). Comparing the effects of two educational methods of intravenous drug rate calculations on rapid and sustained learning of nursing students: Formula method and dimensional analysis method. Nurse Education in Practice, 10(4), 233-237. http://dx.doi.org/10.1016/j. Nurse Education in Practice,
nepr.2009.11.011, PMid:20018563

McMullan, M., Jones, R., \& Lea, S. (2010). Patient safety: Numerical skills and drug calculation abilities of nursing students and registered nurses. Journal of Advanced Nursing, 66(4), 891-899. http://dx.doi.org/10.1111/j.1365-2648.2010.05258.x
National Patient Safety Agency. (2009). Review of patient safety for children and young people. London: National Patient Safety Agency. Available from http://www.npsa. people. London: National Patient Safety Agency. Available from http:
nhs.uk/nrls $/$ mprovingpatientsafety/children-and-young-people/

Nunes, T., Desli, D., \& Bell, D. (2003). The development of children's understanding of intensive quantities. International Journal of Educational Research, 39, 651-675. http://dx.doi.org/10.1016/j.ijer.2004.10.002

Nunes, T., Schliemann, A.D. \& Carraher, D.W. (1993). Street mathematics and schoo mathematics. Cambridge: Cambridge University Press.

Penman, J., \& White, F. (2006). Peer-mentoring program 'pop-up' model for regional nursing students. Journal of University Teaching and Learning Practice, 3(2), 123135. Available from http://ro.uow.edu.au/jutlp/vol3/iss $2 / 6$

QSR International. (2008). Nvivo (Version 8). Available from http://www. qsrinternational.com/products.aspx

Rogoff, B. (1990). Apprenticeship in thinking: Cognitive development in social context. New York: Oxford University Press.

Roth, W., \& Lee, Y. (2007) "Vygotsky's Neglected Legacy": Cultural-historical activity theory. Review of Educational Research, 77, 186. http://dx.doi. org $/ 10.3102 / 0034654306298273$

Simpson, C.M., Keijzers, G.B., \& Lind, J.F. (2009). A survey of drug-dose calculation skills of Australian tertiary hospital doctors. The Medical Journal of Australia, 190(3), 117-120. Available from https://www.mja.com.au/journal/2009/190/3/surveydrug-dose-calculation-skills-australian-tertiary-hospital-doctors, PMid:19203306

Stasz, C. (2001). Assessing skills for work: Two perspectives. Oxford Economic Papers, 3, 385-405. http://dx.doi.org/10.1093/oep/53.3.385

Taylor, J. \& Galligan, L. (2006). Mathematics for maths anxious tertiary students: integrating the cognitive and affective domains using interactive multimedia. Literacy and Numeracy Studies, 15(1), 23-43. Available from http://epubs.scu. edu.au/cgi/viewcontent.cgi?article=1056\&context=tlc_pubs

Tufts, M., \& Higgins-Opitz, S. (2012). Medical physiology education in South Africa: What are the educator's perspectives? African Journal of Health Profession Education, 4(1), 15-21. http://dx.doi.org/10.7196/ajhpe.148

University of Cape Town Division of Clinical Pharmacology. (2010). The South African medicines formulary. (9th edn.). Cape Town: Health and Medical Publishing Group.

Vergnaud, G. (1982). Cognitive and developmental psychology and research in mathematics education: Some theoretical and methodological issues. For the Learning of Mathematics, 3(2), 31-41.

Vithal, R. (2012). Mathematics education, democracy and development: Exploring connections. Pythagoras, 33(2), 1-14. http://dx.doi.org/10.4102/pythagoras. v33i2.200

Wheeler, D.W., Remoundos, D.D., Whittlestone, K.D., Palmer, M.I., Wheeler, S.J., Ringrose, T.R., et al. (2004). Doctors' confusion over ratios and percentages in drug solutions: The case for standard labeling. Journal of the Royal Society of Medicine 97(8), 380-383. http://dx.doi.org/10.1258/jrsm.97.8.380, PMid:15286190, PMCid:PMC1079557 